\title{
The Perceptions and Preferences of the General Foundation Programme Students Regarding Written Corrective Feedback in an Omani EFL Context
}

Soufiane Trabelsi*

The General Foundation Programme, Sohar University, P.O Box: 44 P.C 311, Sohar, The Sultanate of Oman

Corresponding Author: Soufiane Trabelsi, E-mail: strabelsi@soharuni.edu.om

\section{ARTICLE INFO}

Article history

Received: October 25, 2018

Accepted: December 16, 2018

Published: February 28, 2019

Volume: 10 Issue: 1

Advance access: January 2019

Conflicts of interest: None

Funding: None

\section{Key words:}

Written Corrective Feedback,

EFL Writing,

Comprehensive Feedback,

Indirect Feedback,

Unfocused Feedback,

Error Correction,

Peer Feedback

\begin{abstract}
Despite the fact that there has been a growing body of research investigating the effectiveness of written corrective feedback (WCF) for improving L2 learners' writing accuracy, fewer studies have investigated learners' preferences and perceptions of WCF. This paper, which is based on a doctoral research project, reports on an exploratory study that investigated the preferences and perceptions related to the aspects of WCF in an EFL context. Qualitative data was collected from focus groups administered to a sample of intermediate and pre-intermediate General Foundation Programme (GFP) students. The results showed that the students valued feedback and preferred the comprehensive feedback approach. They wanted it to be indirect and unfocused as well as teacher initiated. The findings also showed that they perceived their teacher feedback as timely, involving a variety of techniques, sufficient, efficient, clear, explicit, familiar to them, comprehensive. Despite all that, they sometimes faced some challenges in understanding their teachers' comments. The paper concludes with some implications for teaching and learning.
\end{abstract}

\section{INTRODUCTION}

One of the main goals of the present research study is to examine the foundation year programme students' preferences and perceptions regarding the written corrective feedback they get from their teachers. The researcher believes that the exploration of students' perceptions and preferences with regard to the importance of the role of corrective feedback constitutes an essential source of information to improve foreign and second language learning and teaching. With this in mind, the researcher wants to discover whether the students find their teachers' feedback practices in the classroom efficient as well as whether these practices meet their needs and preferences. What is also a matter of interest to the researcher is to find out whether are potential challenges that the students meet when they receive feedback from their teachers. Through studying the perceptions and preferences of the students and comparing them with the literature and the main findings of Second Language Acquisition (SLA) and WCF research, the researcher will be able to know if WCF in the Omani context is in line with the latest research and best feedback practices and approaches. In other words, the objective is to make sure that WCF is geared towards writing skill development. The study will seek answers to the three following research questions:

1. What are the Omani GFP students' preferences regarding WCF?

2. What are their perceptions of their teachers' $\mathrm{WCF}$ actual practices?

3. What are the implications for providing feedback?

\section{LITERATURE REVIEW}

\section{Defining Feedback}

Feedback means teacher's input to a writer's composition in the form of information to be used for revision (Keh, 1990). It is also identified as being information provided by teachers to help students trouble-shoot their performance (Nicole \& Macfarlane, 2006). Bulks of studies have dealt with the issue of error treatment and numerous terms have been used in this area. Russell \& Spada (2006:134) define corrective feedback as "any feedback provided to learners from any source that contains evidence of learner error of language form. It may be oral or written, implicit or explicit". Although the term 'error correction' has also been used 
instead of 'error treatment' to refer to teachers' responses to learner errors, Lyster et al. (1999) prefer the terms feedback on error, corrective feedback, or error treatment, which reflect the observations made by Long (1977) that what the teacher can do is to provide information to the learner, but it is the learner who will (or will not) eventually 'correct' the error. While error correction implies an evident and direct correction, corrective feedback is a more general way of providing some clues or eliciting some correction besides the direct correction made by the teacher so as to draw learners' attention to the errors (Han, 2002). Ellis et al. (2006: 340) claimed that corrective feedback takes the form of responses to learner utterances that contain error. The responses can consist of (a) an indication that an error has been committed, (b) provision of the correct target language form, or (c) metalinguistic information about the nature of the error or any combination of these.

There is no doubt that feedback is vital for enhancing learning (Anderson, 1982; Brophy, 1981) and L2 writing development (Hyland \& Hyland, 2006). The notion of feedback was first introduced as an important tool of language development in the 1970s. It was advocated by the learner-centered approaches to writing instruction in North American L1 writing classes (p. 1). Before the appearance of the process approach, assigning a grade on the writing script was the only method of responding to students' writing (Grabe \& Kaplan, 1996). It was thought by teachers that when their students would see their errors, they would correct them and know why their writings were marked in red. However, this system of response confused students as viewed by Grabe \& Kaplan (1996).

\section{Feedback in the Teaching of ESL/EFL Writing}

The role, importance, and effect of feedback in ESL or EFL have been key issues in several studies in the teaching of writing (Paltridge, 2004; Reichelt, 1999). The large number of research studies focusing on different types of feedback and their impacts on student writing serve as an evidence that many scholars and researchers believe that feedback plays influential roles in the writing process. Feedback on student writing can make learning more effective as noted by Cardelle \& Corno (1981). The more feedback students receive of their performance, the better they understand what they need to do to correct their mistakes. The understanding of why they made mistakes and how to correct such mistakes helps students correct their mistakes and increase their achievement (Kulhavy, 1977). Student writers who receive feedback will have information about which parts of their texts need to be corrected and improved. Carless (2006) confirms that students who receive feedback during the writing process have a clearer sense of how well they are performing and what they need to do to improve. Feedback can also modify students' thinking or behaviour toward their work and focus their attention on the purpose of writing. Furthermore, feedback can provide assessment on how well the students perform their work or their accomplishment of a given task (Schwartz \& White, 2000) as feedback is meant for helping students narrow down or close the gap between their actual ability and the desired performance (Brookhart, 2003). Teachers are responsible for helping students develop their ability to reach their learning goals through feedback.

Feedback raises students' awareness of the informational, rhetorical, linguistic expectations of the reader (Hedgcock \& Lefkowitz, 1994). As Williams (2005) suggests, feedback in writing can stimulate explicit knowledge of student writers. For him explicit knowledge is the knowledge of language rules that students can articulate and provide reasons that certain rules should be applied. Students who receive feedback will resort to their prior knowledge about language and writing rules that they have learned. In writing, student writers will apply explicit knowledge as stimulated by the feedback on their writing.

Feedback can also increase students' attention on the subject they are writing. In fact, students who receive feedback will pay more attention to what they have written. The feedback that they receive draws their attention to those aspects of their writing that need remediation, and by doing so, they learn how to improve their performance. The increase of attention will lead to writing improvement which can be defined as a gain in accuracy in both form and content of writing as indicated by Ashwell (2000) and Lamberg (1980).

\section{Types of Feedback}

\section{Written corrective feedback}

Two main categories of WCF can be identified: direct and indirect feedback. Direct corrective feedback is referred to as a type of correction that draws students' attention to the error and provides a solution to it. That is to say, the teacher shows students where their errors are and corrects these errors by providing the correct form. As for indirect corrective feedback, it means drawing students' attention to the locations of their errors without providing corrections (Bitchener \& Ferris, 2012).

\section{Direct corrective feedback}

This can take a variety of forms such as a) cross-outs: when the teacher omits any wrong addition from students' original texts, b) rewrites: when the teacher rewrites a word, phrase or a sentence, providing the correct spelling, structure or form on students' original texts, and c) additions: when the teacher adds any missing items on students' original texts (e.g. prefix, suffix, article, preposition, word, etc). As demonstrated by Bitchener \& Ferris (2012), direct corrective feedback aims to help students edit their writing and improve their performance in future tasks. Furthermore, Ferris (2002) contends that this type of feedback is beneficial in dealing with errors of prepositions and other issues of idiomatic lexis. For her, this is helpful in the final stages of the writing process to help students focus on the remaining errors in their texts and refer to them in future tasks. Students' linguistic proficiency is vital to know the amount of direct corrective feedback they receive as advanced learners are more likely to benefit from it. 


\section{Indirect corrective feedback}

This means underlining, circling or highlighting errors on students' original texts, indicating the location of these errors without correcting them. Students are required to study their errors and correct them (Ferris, 2002). Simply put, indirect corrective feedback lays emphasis on the role of students in understanding and correcting their errors rather than being given or shown the corrections. In underlining the writing errors, the students should understand that there is a problem that should be 'fixed.' This can take the form of using lines, circles or highlighting to indicate the location of errors. It is up to the teachers to decide how explicit indirect feedback should be based depending on the goals they want to achieve by providing feedback.

\section{Error correction codes}

These are considered as an implicit type of correction. It involves symbols (e.g. ' ‘ ' for a missing item) and abbreviations (e.g. Pl/Sing for Plural/Singular errors) through which students know the locations and the types of errors on their original texts (Hendrickson, 1984). Hyland (1990) believes that the use of codes in error correction is helpful to teachers as it enables them to provide effective implicit feedback while maintaining the positive effects of error correction. The use of codes minimises the negative psychological effect of red ink on students' texts. By carrying out two studies that investigated the students' preferred types of feedback, Ferris $(1997,2002)$ discovered that students most valued the use of codes and considered implicit written corrective feedback as more effective than other types. There are many teachers who also think that feedback should be provided implicitly through the use of error correction codes as this offers students the chance to consider and correct their errors (Corpuz, 2011).

\section{Peer feedback}

It was assumed that good peer feedback strategies originally used in L1 would be automatically good in L2 as argued by Hyland and Hyland (2006). Research on peer feedback has revealed that it has social and cognitive advantages; for example, through the use of their peers' comments in re-drafting, students can improve their revision and produce better drafts (e.g. Mendonca \& Johnson, 1994; Rollinson, 2005; Villamail \& de Guerrero, 1996). In addition, from a socio-cognitive perspective, peer feedback is a "formative developmental process" (Hyland \& Hyland, 2006:6), which implies that writers develop the ability to exchange views on how they interpret the writings of other students and how other students interpret their writing. In contrast, other studies, have either presented more research questions on peer feedback (e.g., Connor \& Asenavage, 1994) or found that it had a limited use (e.g. Flower, 1994; Spear, 1988).

There are many studies on peer feedback which investigated the interactions of peers in writing sessions. For example, according to Villamil \& de Guerrero (1996), peer responses observed in a writing workshop have a number of qualities, such as social affectivity through which students develop good communication. Hyland (2000), who studied students' interactions in a writing workshop, discovered a positive aspect of peer feedback which was its informality. This means that students spontaneously help and advise each other in the middle of the process of writing rather than at the end of the writing session. Other studies like Rollinson (1998) and Caulk (1994) identified that their students made many valid and correct comments on their classmates' writing. Berg (1999) and Chaudron (1984) point out that students make more specific comments to their peers' writing and, therefore, they consider feedback complementary to teacher feedback.

\section{Students' Preferences and Perceptions}

Studies on students ' views on teachers' WCF have typically focused on one or more of the following issues: students ${ }^{6}$ preferences regarding the types of WCF they would like to receive, students' reactions to teachers' $\mathrm{WCF}$ they have received, the problems students have with their WCF, and how seriously students take teachers" WCF. Like the teachers' beliefs and practices research, studies on students ' views can be categorised into two groups: the first group is made up of researchers like (Cohen, 1987; Leki, 1991; Ferris 1995b; Hedgcock \& Lefkowitz, 1994; Ferris \& Roberts, 2001; Diab, 2005) who investigated students ' preferences in isolation of teachers' ${ }^{6}$ actual practices and these represent the majority of the studies. As a second group, other researchers such as (Cohen \& Cavalcanti, 1990; Lee, 2004) studied the relationship between students ${ }^{6}$ beliefs and their preferences about their WCF and teachers' actual practices. Cohen (1987) investigated students' attitudes, reaction, and problems regarding WCF. The findings of his study suggested that students had trouble understanding or using teacher comments when they were cryptic such as confusing 'or not clear' although they reported that they read and attended to their teacher's WCF. It was concluded that "the activity of teacher feedback as currently constituted and realised may have more limited impact on the learners than teachers would desire" (p. 66). In another study made by Leki (1991), two major issues were explored: a) students' concerns with errors in their writing and b) the best ways -in students' opinion- for teachers to give error feedback. The findings showed that students were very concerned about errors in their writing and aimed to have as few errors as possible. It was also reported by students that teachers should concentrate mostly on their language form errors. In addition, most students preferred the comprehensive WCF over the selective one, and they also preferred the teacher to correct their errors explicitly. In another context, Ferris (1995b) explored students' WCF attitudes, preferences, and reaction by surveying 155 ESL college students in a U.S. university. Ferris found that students read, benefited, and attended to their teachers ' WCF. Teachers were reported to give feedback on the various writing aspects. Students thought that the most important feedback for them was the one on language form. Some problems were faced by the students in understanding the teachers ' WCF. In addition, the students strongly preferred a mixture of praise 
and constructive criticism although they reported that they appreciated positive comments of praise.

As for Hedgcock \& Lefkowitz (1994), while studying the differences in writing contexts and students ${ }^{6}$ motivation through a comparison of the responses between FL classes and ESL students at a U.S. university, they surveyed 247 students about their attitudes to teacher WCF and how teacher WCF had an impact on their views of text quality and their writing processes. Their main finding was the students' concern with issues of grammatical accuracy. Both group of students found it sometimes confusing to interpret the teachers ${ }^{6}$ marks and corrections. Hedgcock \& Lefkowitz concluded that "instructors reported response habits may exert a strong influence on the views of L2 writers about the priority of formal accuracy over the transmission of meaning, and vice versa" (p. 299).

From their part, Ferris \& Roberts' (2001) study came to the conclusion that the students preferred to receive WCF on local issues and considered errors in language form as serious and negatively affected their writing. On the other hand, the students preferred the indirect WCF with error codes attached to other types of feedback. The last study was carried out by Diab (2005) investigating students' opinion about what constitutes effective WCF at the American University of Beirut. The study revealed that most students did not like to have many errors in their text. They also believed that the teachers' WCF should cover a whole range of writing issues including language form, organisation, ideas expressed in the text, and the writing style. In addition, most students favoured the explicit WCF and wanted that the teachers should locate the errors and give correction or clue about how to correct. Finally, most students stated that they read all their teachers' feedback on their writing carefully.

The above literature suggests that L2/FL writing teachers are faced with the dilemma of whether they should correct students' surface errors or not, since students seem to expect this kind of correction while research evidence generally suggests that such feedback is ineffective (Leki, 1991; Radecki \& Swales; 1988; Saito, 1994). Since students' beliefs about and preferences for feedback on writing may influence the degree of effectiveness of such feedback (Schulz, 1996), it is crucial to identify students' attitudes towards error correction and their expectations regarding teacher feedback on their writing.

\section{METHODS}

The method used in the present study is a focus group which is only one instrument among four other ones used in the original study which is exploratory and qualitative in nature. The researcher used a qualitative research method because his target was to investigate the status and the experience of WCF of Omani GFP students. Thus, he employed a student focus group in order to gauge students' input, namely, their preferences and perceptions on WCF in relation to their teachers' WCF actual practices.

\section{Participants}

As far as the student participants were concerned, the researcher, being a writing teacher and a writing skill leader in the intermediate level in the GFP for almost 5 years, asked his writing colleagues to find volunteering students from their classes bearing in the mind that there should be high-achievers, average, and low- achievers among the students. Therefore, 15 groups of students, ranging from 18 to 25 in age, making a total of 75 students expressed their willingness to participate in the study. Most of the students shared the same nationality (i.e., Omani), first language (Arabic), level of education (i.e., three pre-intermediate and 12 intermediate groups), but there were three Sudanese and two Egyptians. After they were approached by their teachers and after expressing their willingness to participate, they accepted to be interviewed. The interview was made in Arabic and recorded after getting the consent of the students. The interviews too place in the students' classrooms when there were no lessons.

\section{Data Analysis}

In the current study, the researcher used thematic analysis as the analytic lens to interpret the data of the teacher interviews and the student focus groups. Braun \& Clarke (2006: 79) define thematic analysis as "a method for identifying, analysing, and reporting patterns (themes) within the data". It minimally organises and describes your data set in (rich) detail. However, frequently, it goes further than this and interprets various aspects of the research topic."

The data analysis process followed the guidelines set by Braun \& Clarke's (2006: 87) six phases of thematic analysis procedure that are depicted in Table 1 which is followed by the the final coding scheme demonstrated by table 2 .

\section{RESULTS}

\section{The Students' Preferences Regarding WCF (RQ1)}

One of the important findings of the focus groups was that most of the students liked to receive feedback because it would help them correct their mistakes (especially spelling), not repeat them again, and that feedback can make them develop their writing skills and improve them. They added that from their teacher feedback they could know the areas to work on.

"We like feedback because this helps us to know and avoid our mistakes and we learn from our mistakes.thus we will not repeat them"

The second aspect of WCF that the students were asked about was their preferences in terms of the focus of feedback. The findings showed that the students had different preferences in relation to this point. The majority of the students considered it essential that all areas (grammar, use and choice of vocabulary, organisation of ideas, organisation of paragraphs, and mechanics) should be focused on by their teachers. They considered all these areas of writing as complementary and since all these elements were mentioned in the marking rubrics, they seemed to be important to them. They added that if some of these aspects were ignored, it would not benefit the students.

"all is important. These are all mentioned in the marking rubrics, so they are all important... when the teacher focus- 
Table 1. Phases of thematic analysis (Braun and Clarke, 2006: 87)

\begin{tabular}{ll}
\hline Phase & Description of the process \\
\hline $\begin{array}{l}\text { 1. Familiarise yourself with your data } \\
\text { 2. Generate initial codes }\end{array}$ & $\begin{array}{l}\text { Transcribing data (if necessary), reading and re-reading the data, noting down initial ideas } \\
\text { Coding interesting features of the data in a systemic fashion across the entire data set, } \\
\text { collating data relevant to each code }\end{array}$ \\
$\begin{array}{l}\text { Collating codes into potential themes, gathering all data relevant to each potential theme } \\
\text { Checking if the themes work in relation to the coded extracts (level 1) and the entire data } \\
\text { 4. Reviewing themes }\end{array}$ & $\begin{array}{l}\text { set (level2), generating a thematic 'map' of the analysis } \\
\text { Ongoing analysis to refine the specifics of each theme, and the overall story the analysis } \\
\text { tells, generating clear definitions and names for each theme } \\
\text { The final opportunity for analysis. Selection of vivid, compelling extract examples, final } \\
\text { analysis of selected extracts, relating back of the analysis to the research question and } \\
\text { literature, producing a scholarly report of the analysis. }\end{array}$ \\
&
\end{tabular}

es just on area we will have problems in the other areas on which he/she doesn't focus on, so the teacher needs to focus on all of these things, all types of mistakes, this is beneficial for us".

Another question was related to the students' preferences in terms of the teacher's way of providing feedback. Most of the students preferred underlining the errors on the page, using error codes and providing comments at the bottom of the paper. They didn't like to see corrections made by the teachers on the writing draft. This was because they didn't want to be spoon-fed and they wanted to learn from their mistakes.

"We want them all together, except correcting the mistakes. We want to the teacher to underline, use symbols and comments only"

Another aspect of WCF about which the students were surveyed was their preferences in terms of the amount of feedback. The majority of the students expected that all the mistakes would be identified because if the teachers ignored some mistakes, the students would repeat them.

"All, so that he will not do them again, because if he gives just part of them, the student can commit those mistakes which were not identified in the first time"

The students were also asked whether they preferred peer feedback. As revealed by the findings, students had different preferences with respect to this aspect of WCF. The biggest number of students liked peer feedback. In other words, they generally preferred to have their papers corrected by other students rather than the teacher. They shared the idea that it was good to have the first feedback from peers and the second one from the teacher.

"Yes, we like peer feedback because we can benefit from their feedback and maybe if I committed some mistakes I am not aware of, so he/she may highlight them for me, so this helps me...but after the paper is checked by the peer it will be checked by the teacher, because students cannot discover all the mistakes, just some of them"

The students stated that they liked peer feedback because each student had different ideas and this could help the students to correct each other. Another reason was that the students might accept feedback from their peers more than the teacher and that the students would learn from each other. Other students, however, preferred the teacher feedback because the students made more mistakes and some of them might not be able to identify all the mistakes.
Table 2: Final coding scheme for the student group interviews

\section{A. Students' learning writing experience}

A1. Importance of learning writing

A2. Challenges in learning writing

B. Students' preferences related to WCF

B1. Feedback liking

B2. Preferred areas of feedback focus

B3. Preferred way of teacher's response to writing

B4. Preference related to feedback amount

B5. Preference related to teacher or peer feedback B5.1. Teacher B5.2. Peers

C. Students' perceptions on teachers' WCF practices

C1. Teachers' explanation of the purpose of feedback

C2. Teachers' timeliness of feedback

C3. Type of feedback used

C3.1. Direct

C3.2. Indirect

C3.3. Mixture of direct and indirect

C3.4. Focused

C3.5. Unfocused

C3.6. Selective

C3.7. Comprehensive

C4. Teacher 's variation of the focus of feedback

C5. Sufficiency of feedback

C6. Clarity of feedback

C7. Students' familiarity with error codes and comments

C8. Effectiveness of feedback

C9. Requirement to write a second draft

C9.1. Compulsory redrafting

C9.2. Optional redrafting

$\mathrm{C} 10$. Consulting the teacher after receiving feedback

D. Challenges in understanding feedback

D1. Ways to overcome difficulties

E. Additional points

F. Recommendations to improve feedback

"It's the teacher's feedback which is better because of experience and expertise"

As far as the students' preferences in terms of who should be the source of feedback, the majority of them preferred the teacher because of the experience, the knowledge and the accuracy related to feedback he/she had.

"We prefer the teacher's feedback because he has more experience and knowledge" 


\section{The Students' Perceptions of their Teachers' WCF Practices (RQ2)}

After having been asked to provide their preferences related to some aspects of WCF, the students were also requested to state their perceptions about their teachers' WCF actual and current practices. To begin with, the students were asked whether their teachers explained to them the purpose and the importance of feedback. The findings showed that most of the students reported that their teachers in the beginning of each semester would do so and they would introduce to them their favourite ways of feedback, the error codes and the types of comments they would incorporate on the writing paper.

"Yes, this is the most important things from the beginning and he tells us his method and his way so that we will be prepared and it will be clear for us"

Having been asked about the timeliness of feedback, all the students stated that their teachers would provide their feedback after a short time and sometimes immediately they did so or at the same day or else in the same class. They added that feedback on the assessments would be given after two to three days. The students expressed their satisfaction with the fact that their teachers were doing their best to provide a timely and immediate feedback because in this way they could remember their ideas and their work as a whole.

"She gives us feedback on our work after a short time... sometimes at the same time in the same class. When we do the quizzes on Thursday, on Sunday or Monday we get the feedback after 2 or 3 days, not a week"

The students were also asked how they perceived the type of feedback used by their teachers. Based on their responses, the students were divided into two groups. The first group declared that the teachers used a variety of techniques. For example, they would display the most common mistakes made by the students, then they would explain how to make the suitable corrections on the whiteboard, etc...

"The teacher always uses a variety of techniques... sometimes for the feedback after the exam, the teacher explains the correction of mistakes on the board, this mistake may have been committed by many students. So, there is a variety of techniques by the teacher from time to time"

The other group mentioned that their teachers would use underlining, error codes and comments. They added that their teachers would use screening of the mistakes on the whiteboard and elicit a discussion and this would benefit all the class.

"The teacher screens the mistakes (the most frequent ones) on the board and we deal with them a classwork, and we correct them together and thus we learn and benefit a lot form that"

Another aspect of WCF about which the researcher sought input was the students' perceptions about varying the focus of feedback. The data collected suggested that nearly all the students stated that their teachers would focus on everything, but some liked it (the majority appreciate that) and others didn't.

"All together, but it's too much, too much pressure on the students, he should divide that, each time he should focus on something"
The students were also enquired about their perceptions about the sufficiency of feedback. Most of the students found their teachers' feedback sufficient and they added that there was no mistake left unidentified on the writing paper. Nonetheless, sometimes small mistakes were skipped by the teachers on purpose so that students would be asked to identify them. The students were satisfied with this practice.

"The teacher focuses on all of them. But normally she should focus on one item at a time"

The other aspect of WCF that the researcher investigated was the students' perceptions about the explicitness and clarity of the feedback. According to the findings, all the groups perceived it as explicit and clear.

"Yes, clear and explicit and he tells us if anyone of you who doesn't understand my feedback please come and see me. If we don't understand his feedback in English sometimes he puts it in Arabic. He uses the board to explain the feedback on certain mistakes"

Nevertheless, sometimes the comments written on the papers could not be understood because of the teachers' handwriting. In that case, the students would ask for clarification in the one-to-one chat with the teachers. The students added that most teachers would tell the students to come and see them if they didn't understand anything in the feedback provided on their work.

"But sometimes the comments we don't understand, they are not clear to us.but for the error codes they are clear because we have the list of symbols and what they stand for"

Another WCF area that the students were asked about was how they perceived their familiarity with the error code and comments. All the focus groups declared that they were familiar with the error codes and the comments used by their teachers. This was because the teachers gave a copy of the codes and explained the comments in the beginning of the semester and at the same time the students were trained on these two, so they got used to them.

"Yes, the same error code, he gave us a table in which all the codes are explained"

Another important question the researcher asked was related to the students' perceptions about the effectiveness of feedback. The entire 15 focus groups confirmed that the feedback was efficient and that they were aware of the progress they were making in writing because of that feedback from one week to another and they were making less mistakes and the quality of their writing was improving. Their progress was mainly related to areas such as grammar, spelling, organisation of ideas and paragraphs, paraphrasing and word order, and sentence structure. They added that most of the time their second draft did not include many mistakes.

"Of course, we made progress at the level of many aspects of writing, and he always mentions to us that we are improving because of feedback"

In addition to the WCF aspects mentioned above, the students were asked about their perceptions about writing a second draft. The findings showed that students had different perceptions of this aspect of feedback and could thus 
be divided into three groups. First, the first group which represented the majority of the students mentioned that the teachers would ask them only for assessments to write a second draft after they corrected the mistakes and without changing the ideas of the first draft, but for the usual practice, the students would not do a second draft; they would just correct the mistakes and then the teacher would give them another topic.

"Yes, if the ideas are good, the teacher asks us to keep them and make only minor changes in the second draft, but if you get a low mark on the writing paper, we have to do the whole writing again.so we do major modifications"

The second group, as a minority, indicated that the teachers would ask them for a second draft and it would always be compulsory.

"Yes, all the time, for the exam papers, yes he does make it compulsory to write a second draft."

The third group declared that writing a second draft was not made compulsory by teachers and it was up to the students to write a second draft.

"The teacher gives us the freedom to make a second draft, he doesn't make it compulsory"

The researcher also asked the students about their perceptions about consulting the teacher for clarifications. All of the students stated that they would consult their teachers for queries seeking explanations on their writing and on the teacher feedback points. In other words, they would discuss everything in details.

"If the mistakes are clear, we don't go to her, but if not, we go to her and we ask here why you underlined this so that we know what to do."

One final question the students were asked included their perceptions about the challenges in understanding feedback. The data indicated that the biggest number of students argued that the teachers' comments could not be understood mainly because of their unclear handwriting.

"Sometimes we don't understand his comments and why he underlined under some mistakes, so we went to him and we asked him and it was ok."

\section{DISCUSSION}

\section{The Students' WCF Preferences}

Among the interesting findings of the current study is that most students considered feedback essential in learning how to write because they needed to know their errors so that they could correct them and improve their writing skills based on the feedback they got from the teachers. This corresponds to the findings in the literature where most previous studies, which investigated the L2 students' attitudes towards their teachers' WCF (e.g. Cohen, 1987; Cohen \& Cavalcanti, 1990; Leki, 1991; Ferris, 1995; Lee, 2004; Grami, 2005; Diab, 2005; Montgomery \& Baker, 2007; Hamouda, 2011; Alkhatib, 2015) highlighted that students considered feedback very important and necessary. Even studies which doubted the usefulness of teachers' WCF (Truscott, 1996) acknowledged that students still appreciated and valued the feedback they received from their teachers. Now to speak about the students' preferences in terms of the focus of feedback, the majority of them wanted their teachers to focus on all aspects of writing, but other students wanted them to focus on grammar and organisation of ideas. These differences in preferences among students were also reflected in the literature. For instance, Schulz's (1996) study findings revealed that regardless of language, the students had a tendency towards a focus on form, which were similar findings to Noora's (2006). Zacharias' (2007) research showed that the students preferred feedback on language more than the feedback on content because they thought grammar feedback was more helpful. As argued by Aridah (2004), it was found that the students liked to have more feedback on grammar than on other aspects. Hammouda (2011) stated that the majority of the learners believed that errors relating to grammatical errors should receive the highest attention for correction. This finding concurs with Halimi (2008) who found that EFL college students tended to value teacher's comments and corrections on grammatical, lexical and mechanical features more than those on content and style.

Speaking about the students' preferences related to the teacher's way of providing feedback, the findings revealed that the students would like their teachers to underline the errors on the page, use error codes and provide comments at the bottom of the paper. This corroborates Leki's (1991) study where it was found that the students preferred to have indirect feedback to direct feedback and they wanted the teacher to give corrections to all of their mistakes, including giving comments on content and ideas as well as on their grammar and surface structure. Ferris (1995) argued that students liked to have their errors all corrected with different types of feedback. Then, Lee (2005) discovered that students wanted their teacher to use error codes and correct all their mistakes. Regarding the amount of feedback, most students prefer that all the mistakes should be identified. This is in line with the literature, for example, in Zhu (2010) 70\% of the students preferred the teacher to correct every mistake. For them, if the teachers were strict with them, they would make greater progress in their future language learning. Similarly, in Amrhein \& Nassaji's (2010) research the students thought that the larger the quantity of corrective feedback, the more useful it was. Moreover, they stated that explicit types of corrective feedback would allow them to remember their errors and understand how to fix them. Most students said that a clue with no correction (i.e., use of error codes) was not useful because the students needed more specific advice. Hammouda (2011) argued that a large number of students $(70 \%)$ liked their teachers to correct all errors in their writings.

As far as peer feedback is concerned, it was found that students were divided into three groups: some students liked peer feedback, while some others preferred teacher feedback and the last group preferred only the good peers to check their papers. Though it was shown by L1 research that students valued peer review sessions in the writing classroom, there was a strong evidence that the L2 (i.e., ESL) context would be quite different. One reason cited for this difference in student preference was that L2 students would traditionally 
consider the teacher as the sole authority in evaluating writing (Rothschild \& Klingenberg, 1990). Oladejo (1993), for example, found that students viewed the teacher as the person best capable of helping students improve their writing. Although students had a strong desire to participate in the correction and revision process (through a preference for use of symbols), they apparently did not see the value of having their drafts evaluated and checked by other students.

Regarding the students' preferences related to teacher or peer feedback, most students chose teacher feedback. In Saito (1994), where the fit between teachers' practices and students' preferences for feedback and the students' strategies for handling feedback on their written work was investigated, it was found that the students preferred teacher feedback to non-teacher feedback (i.e., peer correction and self-correction). This supports Hammouda's (2011) study which showed students' preference for teacher correction. This is also consistent with the results concluded by Radecki \& Swales' (1988) studies which indicated that the majority of the students wanted to be corrected by their teacher and thought that locating, marking and correcting errors were mainly the teacher's job and major responsibility.

\section{The Students' Perceptions of the Teachers' WCF Practices}

All the students were satisfied because their teachers explained the purpose and the importance of feedback in the beginning of every semester. They also added that their teachers explained to them all the details about their way of giving feedback. This is a good indication that the teachers comply with the policies of the university where they work and it is a proof that they are doing their best to make students aware of the importance of feedback for leaning and mastering the writing skills so that they will be prepared for undergraduate studies upon finishing the GFP. With regard to the students' perceptions about the timeliness of feedback, most students agreed that their teacher feedback was timely. This is another good indication that the teachers are efficient in this sense, which can lead to positive results and benefit the students by enhancing their grasp of the feedback. Another WCF aspect is related to the type of feedback used by the teachers. For this, the majority of the students mentioned that the teachers used a variety of techniques like underlining errors, putting error codes and comments on the papers, projecting the mistakes on the board and eliciting a group discussion, then having a whole class correction.

Among other things the students were asked was about their thoughts regarding their teachers' varying the focus of their feedback. According to the findings, nearly all the students stated that their teachers focused on everything, but some of them appreciated that, while others didn't do so. Amrhein \& Nassaji's (2010) study results revealed that the students preferred unfocused, indirect correction concentrating on form rather than on content and organisation. Another finding of the study was that most students had a similar perception that their teacher feedback was sufficient and that all errors were identified on the writing paper for which they felt quite satisfied. They also found that their teacher feedback was explicitly and clearly presented to them although sometimes the feedback comments written at the end of the papers were illegible for them because of the teachers' unclear handwriting. This finding is similar to what Ghazal et al.'s (2014) study showed since students appreciated feedback that conveyed a clear message, and could be understood and followed. Several students stated that when feedback lacked clarity and detailed explanation, they struggled to understand its meaning. Most students reported that they were familiar with the way the teachers would identify errors (underlying and error coding) and put comments at the end of the paper. They added that in the beginning of the semester the teachers usually would deal with all these details and would also train the students on how to use and understand them, so they got used to them.

The other WCF aspect which is of great concern for the study was the extent to which the teachers' feedback was efficient. In fact, the finding was that the students agreed that their teacher feedback was efficient and they justified that by the progress they achieved in writing and by making less mistakes from week to week as well as the improvement of the quality of their writing. This finding which was a positive response and reaction to the teacher feedback is similarly supported in the literature. For example, Mahfoodh's (2011) research, which focused on the attention to learners' perceptions, especially on the affective reaction aroused by WCF provision, showed that learners responded positively to the teacher feedback by rereading the marked essay or expressing happiness towards the correction. Moreover, they perceived the feedback as useful and beneficial for the future. Likewise, Hamouda (2011) reported between 75 and $90 \%$ of positive feelings towards the WCF provided. Zhan (2016) also reported the same finding which was the fact that students had learned a lot from all types of teacher feedback on their final drafts, and were able to improve on corresponding areas of writing in the future. One final study by Ferris (1995) revealed students' positive feelings because of the help gained from their teachers' feedback which made them improve their writing.

Moving to speaking about the students' perceptions about redrafting, students held different ideas regarding that. Some students said that the teachers asked them to redraft only assessments after correcting the mistakes, while others stated that writing a second draft was not made compulsory by the teachers. The last group reported that their teacher would ask them to do a second draft, but sometimes it would be compulsory and sometimes optional. The differences in students' perceptions of redrafting were also reflected in the literature. In fact, Ferris' (1995) research, which was made so as to assess the student reactions to the feedback they received from their teacher, indicated that students would pay more attention to teacher feedback provided on preliminary drafts (and not final drafts) of their essays, and they would find their teachers' feedback useful in helping them to improve their writing. However, some studies revealed negative perceptions of students on redrafting. For example, Radecki \& Swales (1988) argued that the majority of their subjects in their study opposed to revising their composition. 
Now to speak about the students' perceptions about consulting the teacher for clarifications after receiving feedback, all students consulted their teachers for queries seeking explanations on their writing and on the teachers' feedback points. Thus, they discussed everything in details. The students appreciated feedback that conveyed a clear message, and could be understood and followed. This is supported by Ghazal et al.'s (2014) study which revealed that seeking clarification regarding received feedback was considered as an important aspect of learning, especially when it was not specific or if the students had difficulty in understanding it. In the same study students mentioned that the teachers were usually willing to help the students when they contacted them for clarification and this led to their learning.

As a final point, the students reported having challenges in understanding feedback. They argued that the teachers' comments could not be understood mainly because of their unclear handwriting. Some students could not understand all the mistakes identified on the paper. Others did not understand why the teacher had underlined some words on the paper. Another group added that their teacher did not write enough comments. A few students, however, had no challenges in dealing with the teacher feedback. This is different from what is reported by some studies in the literature on this point. For instance, Ferris' (1995) research showed that students had some problems in understanding their teachers' comments. Ferris (2003) stated that students did encounter problems in understanding their teacher comments because the instructions were not clear. This result needs special attention since it suggests that the teachers should train the students well before they start providing them with error correction using codes; otherwise, some misunderstanding may occur between the teachers and the students. As suggested by Hyland (1998), there should be a more open dialogue between teachers and students on feedback in order to prevent any potential miscommunication and misunderstanding. Ferris (2003) argued that because of the challenges that students may face in understanding teacher feedback, they may fail to interpret a teacher's question as a suggestion for information, and it would not be surprising to find that students ignored it when they did a revision of their work.

\section{CONCLUSION}

The objective of the present study was twofold: to investigate the GFP students' perceptions and preferences regarding WCF and to find out whether they face challenges in coping with their teachers' feedback. The findings revealed that most of the students firmly believed in the importance of feedback and shared the view that feedback could serve them many purposes. They also viewed it as being timely, comprehensive, sufficient, explicit, clear, effective, familiar for them in terms of its error code and comments. For them, their teachers employed a variety of techniques while providing feedback on their students' writings. Yet, the only aspect of WCF about which the students' perceptions differed was writing a second draft. Indeed, some students were motivated to redraft their writings while others were not. This was mainly due to the inconsistency among the teachers in imposing redrafting on the students because of the constraints that were faced such as the huge number of students in each class, teacher load, the heavy schedule of assessments and time pressure.

As far as the students' preferences with regard to WCF, the findings showed that they had common preferences related to some aspects of WCF such as appreciating and valuing of feedback, having their errors underlined and coded including writing comments, receiving comprehensive feedback, getting a teacher-initiated feedback first. However, they had different preferences regarding the focus of feedback. In fact, some students preferred feedback to focus on all aspects of writing (i.e., grammar, vocabulary, mechanics, organisation, spelling), while others wanted only some of these areas to be focused on.

The second objective which concerns the challenges that the students met in coping with the teachers' feedback, the findings indicated that the students found it difficult in understanding some of the teachers' feedback comments. They also found it challenging in coping with the one-to-one consultation with the teacher.

In order to have an effective feedback, GFP teachers should take the above mentioned insights on the students' preferences and perceptions into consideration. This is corroborated in the literature as discussed in many occasions in the current paper. When students' input on WCF is taken into account, it will not be teacher-centred and it will engage the students because they can contribute to it and their voice can be considered.

\section{REFERENCES}

Alkhatib, M. N. (2015). Written corrective feedback at a Saudi university: English language teachers' beliefs, students' preferences, and teachers' practices. Unpublished $\mathrm{PhD}$ Thesis, the University of Essex.

Amrhein, H. R. and Nassaji, H. (2010). Written corrective feedback: What do students and teachers prefer and why? Canadian Journal of Applied Linguistics, 13, 95-127.

Anderson, J. R. (1982). Acquisition of cognitive skill. Psychology Review, 89, 369-406.

Aridah, (2004). Students Preferences and Reaction to Teacher Feedback. Malang: State University of Malang Press.

Ashwell, T. (2000). Patterns of teacher response to student writing in a multiple-draft composition classroom: Is content feedback followed by form feedback the best method? Journal of Second Language Writing, 9(3), 227-257.

Berg, E. C. (1999). The effect of trained peer response on ESL students' revision types and writing quality. Journal of Second Language Writing, 8, 215-241.

Bitchener, J. \& Ferris, D. R (2012). Written corrective feedback in second language acquisition and writing. New York: Routledge.

Braun, V. \&. Clarke, V. (2006). Using thematic analysis in psychology. Qualitative Research in Psychology, 3(2), $77-101$. 
Brookhart, S. M. (2003). Developing measurement theory for classroom assessment purposes and uses. Educational Management: Issues and Practice, 22(4), 5-12.

Brophy, J. (1981). Teacher praise: A functional analysis. Review of Educational Research, 51, 5-32.

Cardelle, M. A. \& Corno, L. (1981). Effects on second language learning of variations in written feedback on homework assignments. TESOL Quarterly, 15(3), 251-261.

Carless, C. (2006). Differing perceptions in the feedback. Studies in Higher Education, 31(2), 219-233.

Caulk, N. (1994). Comparing teacher and student responses to written work. TESOL Quarterly, 28(1), 81-188.

Chaudron, C. (1984). The effects of feedback on students' composition revision. RELC Journal, 15(2), 1-15.

Cohen, A. D. (1987). Student processing of feedback on their compositions. Learner Strategies in Language Learning, 57-69.

Cohen, A.D., \& Cavalcanti, M.C. (1990). Feedback on compositions: Teacher and student verbal reports. In B. Kroll (Ed.), Second language writing: Research insights for the classroom (pp. 155-177). Cambridge: Cambridge University Press.

Connor, U. M. \& Asenavage, K. (1994). Peer response groups in ESL writing classes: How much impact on revision? Journal of Second Language Writing, 3, 257-276.

Corpuz, V. F. (2011). Error correction in second language writing: Teachers' beliefs, practices and students 'preferences. Unpublished Master's Thesis, Queensland University of Technology.

Diab, R. L. (2005). EFL university students' preferences for error correction and teacher feedback on writing. TESL Reporter, 38(1), 27-51.

Ellis, R., Loewen, S., \& Erlam, R. (2006). Implicit and explicit corrective feedback and the acquisition of L2 grammar. Studies in Second Language Acquisition, 28(2), 339-368.

Ferris, D. R. (1995a). Can advanced ESL students be taught to correct their most serious and frequent errors? CATESOL Journal, 8(1), 41-62.

Ferris, D. R. (1995b). Student reactions to teacher response in multiple-draft composition classrooms. TESOL Quarterly, 29, 33-53.

Ferris, D. R. (1997). The influence of teacher commentary on student revision. TESOL Quarterly, 31, 315-339.

Ferris, D. R. (2002). Treatment of error in second language writing classes. Ann Arbor, MI: University of Michigan Press.

Ferris, D. R. (2003). Response to student writing: Research implications for second language students. Mahwah, NJ: Lawrence Erlbaum.

Ferris, D. R. \& Roberts, B. (2001). Error feedback in L2 writing classes: How explicit does it need to be? Journal of Second Language Writing, 10(3), 161-184.

Flower, L. (1994). The construction of negotiated meaning: A social cognitive theory of writing. Carbondale, IL: Southern Illinois University Press.

Ghazal, L., Gul, R., Hanzala, M., Jessop, T. \& Tharani, A. (2014). Graduate students' perceptions of written feedback at a private university in Pakistan. International Journal of Higher Education, 3(2), 13-27.

Grabe, W. \& Kaplan, R. B. (1996). Theory and practice of writing: An applied linguistic perspective. London: Longman.

Grami, M. (2005). The effect of teachers' written feedback on ESL students' perception: A study in a Saudi ESL university-level context. Annual Review of Education, Communication and Language Sciences, 2, 18-41.

Halimi, S. S. (2008). Indonesian teachers' and students' preferences for error correction. Wacana, 10(1), 50-71.

Hammouda, A. (2011). A study of students and teachers' preferences and attitudes towards correction of classroom written errors in Saudi EFL context. English Language Teaching, 4(3), 128-129.

Han, Z. H. (2002). Rethinking of corrective feedback in communicative language teaching. RELC Journal, 33, 1-33.

Hedgcock, J. \& Lefkowitz, N. (1994). Feedback on feedback: Assessing learner receptivity in second language writing. Journal of Second Language Writing, 3, 141- 163.

Hendrickson, J. M. (1984). The treatment of error in writing work. In S. McKay (Ed.), Composing in a second language (pp. 145-159). Rowley MA: Newbury House.

Hyland, F. (1998). The impact of teacher-written feedback on individual writers. Journal of Second Language Writing, 7, 255-286.

Hyland, F. (2000). ESL writers and feedback: Giving more autonomy to students. Language Teaching Research, 4(1), 33-54.

Hyland, K. \& Hyland, F. (2006). Feedback in second language writing: Contexts and issues. Cambridge: Cambridge University Press.

Keh, C. (1990). Feedback in the writing process: A model and methods for implementation. ELT Journal, 44, 94-304.

Kulhavy, R. W. (1977). Feedback in written instruction. Review of Educational Research, 47(1), 211-232.

Lamberg, W. (1980). Self-provided and peer-provided feedback. College Composition and Communication, 31(1), 63-69.

Leki, I. (1991). The preferences of ESL students for error correction in college-level writing classes. Foreign Language Annals, 24(3), 203-218.

Lee, I. (2004). Error correction in L2 secondary writing classrooms: The case of Hong Kong. Journal of Second Language Writing, 13(4), 285-312.

Long, M. (1977). Teacher feedback on learner error: Mapping cognitions. In C. Y. H. Brown (Ed.), On TESOL 77 (pp. 278-294). Washington D.C.: TESOL.

Lyster, R., Lightbown, P. M., \& Spada, N. (1999). A response to Truscott's 'What's wrong with oral grammar correction'. The Canadian Modern Language Review, 55(4), 457-467.

Mahfoodh, O. (2011). A qualitative case study of EFL students' affective reactions to and perceptions of their teachers' written feedback. English Language Teaching, 4(3), 14-25.

Mendonca, C. \& Johnson, K. (1994). Peer review negotiations: Revision activities in ESL writing instruction. TESOL Quarterly, 28, 745-769. 
Montgomery, J. L. \& Baker, W. (2007). Teacher-written feedback: Student perceptions, teacher self-assessment, and actual teacher performance. Journal of Second Language Writing, 16, 82-99.

Nicole, D. J., \& Macfarlane-Dick, D. (2006). Formative assessment and self-regulated learning: A model and seven principles of good feedback practice. Studies in Higher Education, 31(2), 199-218.

Noora, A. (2006). Iranian non-English majors' language learning preferences: The role of language institutes. Retrieved from http://www.asian-efl-journal.com/site map.php (accessed 5/1/2016).

Oladejo, J. A. (1993). Error correction in ESL: Learners' preferences. TESL Canada Journal, 10, 71-89.

Paltridge, B. (2004). Approaches to teaching second language writing. $17^{\text {th }}$ Educational Conference, Adelaide. Retrieved from https://celta.wikispaces.com/file/view/ Paltridge.pdf/30724017/Paltridge.pdf

Radecki, P. \& Swales J. (1988). ESL student reaction to written comments on their written work. System, 16, 355-365.

Reichelt, M. (1999). Toward a comprehensive view of L2 writing: Foreign language writing in the U.S. Journal of Second Language Writing, 8(2), 181-204.

Rollinson, P. (1998). Peer response and revision in an ESL writing group: A case study. Unpublished $\mathrm{PhD}$ Thesis, Universidad Autonoma de Madrid.

Rollinson, P. (2005). Using peer feedback in the ESL writing class. ELT Journal, 59(1), 23-30.

Rothschild, D. \& Klingenberg, F. (1990). Self and peer evaluation of writing in the interactive ESL classroom: An exploratory study. TESL Canada Journal, 8, (1), 52-65.

Russell, J., \& Spada, N. (2006). The effectiveness of corrective feedback for the acquisition of L2 grammar:
A meta-analysis of the research. In J. N. Ortega (Ed.), Synthesizing research on language learning and teaching (pp. 133-164). Amsterdam: John Benjamins Publishing Company.

Saito, H. (1994). Teachers' practices and students' preferences for feedback on second language writing: A case study of adult ESL learners. TESL Canada Journal, 11(2), 46-70.

Schulz, R. A. (1996). Focus on form in the foreign language classroom: Students' and teachers' views on error correction and the role of grammar. Foreign Language Annals, 29(3), 343-364.

Schwartz, F. \&. White, K. (2000). Making sense of it all: Giving and getting online course. In K. W. Weight (Ed.), The online teaching guide: A handbook of attitudes, strategies, and techniques for the virtual classroom (pp. 57-72). Boston: Allyn and Bacon.

Spear, K. (1988). Sharing writing: Peer response groups in English classes. Portsmouth, NH: Boynton/Cook.

Villamil, O. S. \& De Guerrero, M. C. M. (1996). Peer revision in the L2 classroom: Social-cognitive activities, mediating strategies, and aspects of social behaviour. Journal of Second Language Writing, 5(1), 51-75.

Williams, J. (2005). Teaching writing in second and foreign language classroom. Boston: McGraw Hill.

Zacharias, N. T. (2007). Teacher and student attitudes toward teacher feedback. RELC journal, 38(1), 38-52.

Zhan, L. (2016). Written teacher feedback: Student perceptions, teacher perceptions, and actual teacher performance. English Language Teaching, 9(8), 73-84.

Zhu, H. (2010) An analysis of college students' attitudes towards error correction in EFL context. English Language Teaching, 3, 127-130. 